\section{CLINICAL OBSERVATIONS ON ESSENTIAL HEMATURIA *}

WILJIAM F. BRAASCH, M.D.

Attending Physician to the Mnyo Clinic, St. Mary's Hosplital ROCHESTHR, MINN.

For want of a more accurate term, I have retained that of "essential" for the type of hematuria which has not as yet been explained by any of the definitely established renal conditions causing hemorrhagic urine. The term "essential" should be limited to those cases of hematuria in which there is neither clinical evidence of renal insufficiency, visible organic change in the renal parenchyma nor any evidence of renal infection. The operative records of the Mayo clinic up to June 1, 1913, show twenty-six patients operated on for renal hematuria for which no evident cause could be found, and the clinical records show fifty-one patients not operated on in which the clinical diagnosis of essential hematuria was evident.

\section{SYMP'TOMATOLOGY}

Sex.-Of the 77 patients, 58, or 75 per cent., were males and 19 , or 25 per cent., females. The preponderance of males is noteworthy and is in keeping with that of renal infection occurring in the male.

Age.-At the time of examination 6 patients were under 30 years, 10 between 30 and 40 , 24 between 40 and 50,17 between 50 and 60 , and 12 over 60 . The majority of cases occurred in persons between the ages of 40 and 50, while only a small number of patients were below 30 years.

Iocalization.-On cystoscopic examination the disease was localized to the right side in 51 cases and to the left sicle in 26. Pain was described as a dull ache across the sacrum in 10 of the 77 cases, in either lateral abdomen in 6 cases, but never to such a degrec as to be of any practical significance. It was described as severe in 5 cases, and then only with hematuria, the pain evidently being caused by blood-clots blocking the affected ureter.

Duration of Symptoms.-Of the 26 patients operated on, hematuria had first appeared over a year before in 16 , or 61 per cent., over 5 years in 10 cases, or 38 per cent., and 15 years or more in 5 cases, or 19 per cent. It had continued prior to operation for a year or more in 5 (ases, or 19 per cent., over 3 months in 18 , or 69 per cent., and over a month in all but three of the cases. Of the 51 patients not operated on, hematuria was noted less than three montlus before in 23 cases, over a year before in 12 , or 23 per cent., over 5 years in 10 , or 19 per cent., and over 10 years ago in 5 , or 9 per cent.

Physical Findings.- In three of the cases the affected kidneys appeared to be enlarged, on palpation, as though there might be tumor, but at operation they were found to be large, normal kidneys. In three other cases the kidney was described as low-lying and movable, in two of which the condition was found bilateral. Evidence of a central nervous lesion or marked neurosis was absent in all. In the 34. cases in which the blood-pressure was recorded the average was 132 ; in 2 cases it was more than 150. Ophthalmoscopic findings were practically negative in all. The general strength was lowered to such a clegree that 19 of the 26 patients operated on were unable to carry on their daily occupation and only 6 of the 51 patients not operated on. 'The average hemoglobin estimate of the patients operated on was 63 per

- IRead in the Scetion on Gentto-Urinary Discases of the Ameri. con Miedien Associatlon. nt the Slxty-Fourth Aunual Session, bele at Alinneapolls, Junc, 1913 cent., while that of the patients not operater on was $S+1$ per cent.

Urinalysis.-The specific gravity of twonty-four-hour specimens taken in 21 of the cases in which there was operation was below 1.015 in but 3 cases. In the other cases tlie avernge was 1.023 . Albumin in varying amounts was found in all the eases in which operation was performed, as was to be expected as a result of the hematuria present at the time of examination. A few hyaline casts were found in 4 ases and occisional granular casts in 2 cases. A few microscopic pus cells were found in 5 of the cases in which the patients were not operated on.

Hematuria.-The hematuria was reported as being present in a marked degree in 54 cases, or 70 per cent., and but slightly in 23 cases, or 30 per cent. In 63 cases. it varied in degree at various times.

Pyelogram.-Clhe pyelogram with essential hematuria necessarily shows the outline of a normal pelvis. Evidence of abnormality would call our attention to the probability of some other condition being present even though no other symptoms were found.

\section{DIFHERENTIAL DIAGNOSIS}

The diagnosis of essential hematurin is most often confused with that of chronic nephritis, infectious nephritis, pyelitis, neoplasm, tuberculosis and lithiasis.

Chronic Nephritis.-The hematuria of nephritis is sharply defined from that of essential hematuria. It is usually present in a lesser degree and may vary from day to day. Scanty urine and the presence of many granular casts, edema, headache, increased arterial tension, lesions in the retina, any or all of which characterize nephritis, are necessarily absent with essential hematuria. Borderline cases which may have some charncteristics of both conditions rarely occur. The conditions are usually widely separated clinically and it is difficult to understand from a clinical point of view how any relationship can be traced between the two conditions. When hematuria occurs with chronic nephritis, it is usually regarded as a terminal symptom, whereas it may be disregarded in a case of proved essential hematuria.

Infectious Nephritis. - Chronic infection in the kidney may be the cause of hematuria often resembling that of essential hematuria. It may appear insidiously without clinical evidence of infection other than microscopic pus and bacteria in the urine. More often, however, it is characterized by attaçks of dull pain referred to one or both kidueys, chills and fever, together with microscopic pus, bacteria and gross hematuria. The hematuria is usually slight or comparatively moderate in degree. It may be present only during the acute attack or it may appear irregularly without the clinical eviclence of infection. Pain, which is usually slight with essential hematuria, may be marked with the infectious' nephritis, and is more often accompanied with fever and chills and other evidence of infection. The infecting organism can usually be identified in the urine taken under aseptic precautions. As Billings ${ }^{1}$ has reported, the hematuria and other symptoms may lisappear on administering autogenous vaccine. This was the result in one of four cases in which the vaccine was tried at the Mayo Clinic. The clinical evilence of renal insufficiency is usually absent until late in the discase. Although this condition is more often bilateral, four patients have been operated on in whom the elinical findings and subsequent course would indicate that the infection was unilateral. In these cases the kidney was found at operation to be

1. Blltings : Am. Joul. Med. Sc., 1010, exxxlx, 625. 
smaller than normal, soft and irregular in contour. On scetion cicatricial changes of evident previous infection were apparent. Needless to say, with essential hematuria the urine should be free from pus and bacteria. 'The cicatricial changes in the pelvic outline of infectious nephritis as shown in the pyelogram are not usually extensive enough to be of diagnostic significance.

Blecing Pyelitis.-Hematuria is occasionally present with chronic infection of the renal pelvis. It occurs with a chronic indolent infection confined largely to the pelvis and without much active destruction of the substance of the kidney. 'The infective process may involve the tissues about the renal pelvis and the adjacent ureter to a varying degree. Subsequent ricatrefial contraction and adhesions will bind the pelvis and renal pedicle firmly and distort the pelvic lumen. When the upper ureter is involved it may either become dilated or partially constricted as a result of the cicatricial process. The mucosa of the pelvis in such cases shows irregular arens of inflammation and congestion which bleed on tonching, and on close inspection appear to be granular. Between these areas the mucosa may be seen pale and glistening as the result of the chronic cicatricial changes. On microscopic examination the grenular unucosa shows a papillomatous proliferation of cells. The latter condition was first described by H. Chiari" and recently by von Frisch, and is called pyelitis granulosa. Occasionally the papilJae alone are involved and the hematnria may result from the consequent papillitis. The hematuria which is seen occasionally with extensive hydronephrosis is caused by a similar condition in the mucosa, as the evident result of a chronic indolent infection. Clinically, hematuria of pyelitis may be subjectively differentiated from the essential hematuria by the character of the pain which frecuently accompanies pyelitis. It is usually a dull, persistent pain with jregular acute exacerbations occurring without evident cause. Pain with essential lematuria is exceptional and occurs only as the result of an occluding hlood-clot. Bleeding pvelitis might be conflusel with that of infectious nephritis, which, however, oceurs mole often in typical attucks with chills, fever ancl slight hematuria. On urinalysis microscopic: pus will always be found present with pyelitis gramulosa. Because of the indolent type of the infection but a few pus-cells may be present among the red blood-cells. Needless to siy, only the specimen obtained by meteral catheterization is of value, because pus-cells in the voided urine nay come from any extral'enal source. The most aceurate methou of slifferential diagnosis is ohtuined through pyelography. The outline of the pelvis and adjacent meter will appear irregularly narrowed and dilated. One or more of the calices may be irregularly dilated; more often they are effaced.

Neoplasm.-Although the hematuria of neoplasms is often present to a marked degree like that of essential hematuria, it usually persists but a short time and appears at irregular jntervals. Unfortunately the ocensional short hemorliage does not cause the average patient to consult a physician so of ten as the protracted one. The prescnce of tumor will usually identify the nature of the hematuria, but in twelve of ninety-one pritients operated on for malignant tumor of the kidney at the Nayo Clinic, definite tumor could not be dletermined elinically. It is this group of tmmols which is ansily confused with essential hematuria. Two methods are available in identifying the existence of a surgical

2. ('hlari, H.: Mrd. Jahub., 1881, 9.

3. Von Fifsele Verhandluagen d. doutschen Gesellsch. f. Urolog. 11. Lungress in Beriln, April 10-2:, 1000, 270. condition, namely, pyelography and the renal functional estimate. It has been slown that the kidncy with essential hematuria will not manifest any marked decrease in functional activity as measured by the secretion of phenolsulphonephthalein injected. It has been my experience that non-infected neoplasms without hematuria will show decrease in function in but 25 per cent. of cases. Unfortunately, renal tumors too small for definite palpation would show even a smaller percentage. Furthernore, profuse hemorrhage offers considerable technical difficulty in the accurate estimation of the amount of dye sccreted. With marked comparative reduction of functional activity of the bleeding lidney, however, the existence of neoplasm should be suspected. lyelography will more of ten be of value in ascertaining the existence of neoplasm by demonstrating an abnormal outline of the renal pelvis subsequent to tumol-retricetion. While recognizable deformity of the pelvis may be demonstrated in over two-thirds of tumors of the kidney that couse to operation, early tumor may not show recognizable deformity. Nevertheless, any tumor that is so fur advanced as to cause hematuria will probably cause recognizable pelvic deformity. Fven after all possible clinical evidence has been obtained, the question will often be raised whethèr or not operation is indicated. 'Tumor of the kidney was discovered at operation in two cases in which the clinical evidence rather silggested essential hematuria.

Renal Tuberculosis.-Oceasionally the first and only evidence of renal tuberculosis is hematuria. In such cases the hematuria will usually be well marked and persist but a day or two, often showing but one hemorrhage. In the absence of pus in the urine and other evidence of tuberculosis on physical and cystoscopic examination, its existence could easily be overlooked. If there is any probability of tuberculosis, guinea-pig inoculation should always be made. Of three cases of hematuria regarded on clinical examinntion as being essential, two were proved to be tuberculous on subseguent examination, and in one the patient was reported as having died of renal and pulmonury tuberculosis.

Lilhiasis.-A small stone pocketed at the end of a calix may be the canse of an otherwise symptomless hemnturia and remain undiscovered even with the most careful rocntgenographic technic. Upinalysis will usually show the presence of old blood-cells but no pus. $A$ careful search should also be marle for crystals, particularly those of ealcium oxalate, which, if present in a considerable quantity, would be very suggestive of the existence of stone. On exploring in two cases regarded eliuically as essential hematuria, such a stone was found at the end of a calix in one. In the other case a stone 2 cm. in diameter was found in the cortex, which, becanse of its solt (haracter and the mustial obesity of the patient, did not slow in the roentgenograin. 'T'wo more patients regarded clinienlly as having essential hemnturia but not operated on reported having passed smull stomes several months after returning to their homes.

Renal Vavia.-With the publication of a case showing angioma of the renal papilla, Fenwicke alvanced a new explanation for a certain group of cases which land hitherto been called essential hematuria. It was at first: believed that this condition would explain a large proportion of cases of essential hematuria. Recently a number of such cases have been reported in American literature. 'These might give the impression that the condition is a common one. Any jeport of such a condition withont a microscopic section showing the dilated condition of

4. Fenwfek: Brlt. Med. Jour., Juue 17, 1905. 
the papillary blood-vessels cannot be of accurate value. Clamping the pedicle and consequent congestion of the tissue of the kidney may cause the papillac to appear so engorged as to give an impression of abnormality. 'l'rue angioma is a comparatively rare condition and can explain but a very small percentage of bleeding kidneys. One such case has come under our observation in which microscopic section showed the typical dilated structure of the blood-vessels. 'The condition may be readily confused with the varicose condition of the blood-vessels adjacent to the pelvis as the result of insidious infection in the pelvis and surrounding tissues. With infection of the tissues the veins of the papillae will occasionally be found dilated on microscopic section. Ieukoplakia of the pelvis was discovered on exploring the pelvis of the kidney in a case believed on clinical examination to be bleeding, because of essential hematuria. Pyelograpliy will not as a rule be of much value in identifying the changes which affect the pelvic ontline but moderately.

Afer-Course.-Of the 20 patients operated on, nephrolomy was performed in 12 cases and neprectomy in 16 . Exploration was made in 1 case. In 2 of the 12 patients in whom nephrotomy was made the hematuria persisted to such a degree that nephrectomy was necessary in 1 case three montlis and the other four months after the first operation. In 1 case of nephrectomy hemorrhage through the wound persisted necessitating nephrectomy two day's after nephrotomy. In 1 other case of neplrotomy made four years ago the patient reports occasional hematuria in a diminished degree. The 8 patients reporting recovery following operation were operated on 1 six years, 1 four years, 2 three years, 2 two years, and 2 one year ago. In the patient operated on four years ago, hemorrhage was reported occurring a year after operation but none since then. Of the 16 cases of nephyectomy, 1 patient died elsewhere six months after operation from some unknown cause, and 1 was not heard from. Fourteen patients are living and are reported in excellent health 1 twelve years, 1 eleven years, 3 eight years, 1 nine years, 2 six years, 2 four years, 1 three years, 1 two years and 3 two years after operation. It will be noted, therefore, that nephrotomy is not to be regarded as a certain method of cure. The fact that recovery followed in 8 , or 67 per cent. of the cases, slould recommend it, provided the allected, kidney appear's quite normal on exploration. On the other hand, the excellent results obtained from nephrectomy should recommend such procedure providing the hemorrhage prior to operation had been severe enough to warrant it, that the patient's general condition was otherwise good and that the functional activity of the other kidney was previously ascertained. Of the 51 cases not operated on, we were able to trace but 44 . In 26 of these cases the affected kidney was merely catheterized, with cessation of hematuria following. 'This cessation of symptoms remained permanent in but 4 cases. In 18 cases the pelvis was overdistended with methylene blue or colloidal silver solutions with permanent cessation of hematuria in but 3 cases. In 6 eases epinephrin (adrenalin chlorid P. D. \& Co.) in solutions in $1: 2,000$ as advanced by Young was introduced into the pelvis of the affected kidney. Recurring hematuria was reported in all cases except one treated six montlis ago. In one of two cases treated three years ago, Jematuria was reported stopped over a period of one and one-half yeal's. Horse-serum was injected in two cases, and hmman serum, as suggested

5. Foung, II ugh II.: 'Tlue Cure of Unflateral Renal liomaturia by injection of Adremilin through a Ureter Catheter, The JouksaL A. M. A., Nity 18, 1007, p. 1054 by Barringer, ${ }^{\circ}$ in one case with no immediate cessation of symptoms.

Treatment.-From the foregoing results it would scem advisable, as a rule, to treat essential hematuria conservatively. Ncedless to say, every means of diagnosis should be employed before exploration is undertaken. It has been our rule not to advise surgical exploration unless the hematuria was so marked as to incapacitate the patient or whenever evidence existed which suggested the possibility of neoplasm. The question of whether or not to explore for a possible neoplasm is one of the most diflicult problems to solve in the clinical examination of hematuria. The possibility of renal tumor in a patient over 40 years of age whose general condition is below par and who has no clinical evidence of nephritis would justily surgical exploration even though the hematuria itself were not severe enough to warrant it. lexploration is not justifiable when no clinical evidence exists other than one or two spells of hematuria. In such cases ureteral catheterization or any of the various methods of renal pelvic irritation, such as overdistention, pyelography, epinephrin, etc., should first be tried, or, as has been recently suggested, the injection of blood-serum. An occusional moderate hematuria without other clinical symptoms recurring alter these measures have been tried should not necessarily require any form of treatment. When the hematuria has incapacitated the patient, however, or when neoplasm is regarded as possible, exploration is indicated. The good results obtained from nephrotomy would justify its use provided nothing is found wrong with the kidney on exploration. If, on exploration, however, any evidence of previous infection or tissue-destruction exists or if nephrotomy should fail to stop the bleeding, nephrectomy is indicated.

Eliology.-Of the various etiologic factors that have been advaneed to explain essential hematuria, nephritis scems at present to have the most supporters. Of recent years pathologic evidence in support of this theory has been advanced by Israel, Niehols, Kretschmer, Kapsammer, Stoerk and others. Microscopic examination of bleeding kidneys removed at operation and postmortem discloses areas of greater or lesser extent with varying degrees of nephritis in practically every case if carefully scarched for. An examination of the pathologic material of bleeding kidneys removed at the Mayo Clinic shows eleven specimens. Of this number, three show nothing but a few glomeruli with cicatricial changes, one is quite normal on serial section, and the others show moderate degrees of increase of interstitial connective tissue as well as glomerular chañges. None of them show the marked destructive changes found with clinical chronic nephritis. Section of kidneys removed in the last 320 post-mortem examinations of patients (Broders) who had no clinical evidences of advanced renal disease, shows some evidence of nephritis in 200 cases, or 63 per cent. In none of these cases liad hematuria ever been reported and none had clinical evidence of nephritis. On comparing microscopic sections it was impossible to differentiate the character of the microscopic changes found in the bleeding and non-blecding kidneys. It is quite evident that there must be some other factor involved which causes one of two kidneys to bleed when the microscopic changes are quite similar. Because nephritic changes are found in a bleeding lidhey it does not necessarily follow that nephritis cuuses the hematuria.

The elinical evidence obtained on examination and observation of the after-eourse of patients suffering with

C. Barringer: Am. Jour. Urol., May, 1912. 
essential hematuria does not support any nephritic etiology. Four of the patients operated on and three of those not operated on gave listories of hematuria of filteen years or more prior to examination. If the hematuria were one of the earliest symptoms of nephritis the progress has been rather slow. Furthermore, the number of patients who have been entirely well five years or more since neplirectomy is not in keeping with the usual course of a patient suffering with chronic nephritis from whom one of two discased kichey's are removed. Whatever the cause of the hematuria may be, if systemic, it apparently cloes not tend to shorten life, at least to any great extent. In support of the nephritic theory it has been advanced that many cases show traces of albuunin or occasional casts in the urine in the interval when no hematuria is present. 'The routine examination of the urine of five thousand patients examined consecutively at the Mayo clinic during the past year shows a trace of albumin in 1,450 , or $\$ 9$ per cent. Less than a liundred of these patients had any clinical evidence of nephritis and none of them lad essential hematuria. 'The overwhelming proportion of patients with albuminuria as compared with those suffering from hematuria demands further explanation than that of nephritic change. Furthermore, the term "nephritic" is an unfortunate one for this type of hematuria now called "essential," and tends to confuse it with the hematuria accompanying acute and chronic nephritis, which is clinically quite distinct.

\section{ABSTRRACT OF DISCUSSION}

Dr. J. R. Cavik, St. Louis: There has been a growing tendency to attribute many of these cases of renal bleeding to nephritis, and I was glad to hear Dr. Bransch condemu this and also to hear him advocate conservatism in treatment. There is no disense-if we may call it a disense-which requires more careful diagnosis than this.

Two cases within the last year have exemplified this to me. Both of them presented clinical evidences of nephritis-albu. min, casts, high arterial tension, and general evidences of nephritis-and both have cleared up immediately after pelvic injections of epinephrin (adrenalin). I think that we have to be extremely careful, for so many men are advising immediate renal decapsulation or nephrotomy. Before any such procedure is ever attempted, I think one should always try to eliminate the renal pelvis as a source of the bleeding by injections into the renal pelvis of epinephrin, of horse-serum, or of something of the sort.

Dr. O. S. Fowtek, Denver: I should like to ask how many of the cases in which operntion was refused were bilateral? In looking for casts in these enses of hematurin, we should never centrifuge the urine. If we centrifuge it we get so many blood-cells that they olscure all the easts. That was the erse in a jationt of mine. The exumination was made by a competent pathologist who fuiled to find casts. He had centrifuged the urine. An uncentrifuged specinen showed casts.

Dr. A. L. Cuver, Boston: It seems to me that a focul nephritis, not an interstitinl nephritis, might explain some of these cases of hematuria. A patient I saw two years ago had had this bleeding for sixteen months. The hemoglobin percentage was low. I cut down on the kidney. 1 thought that I con!d feel a nodule in it, and therefore removed the kidney. It showed alssolutely nothing in the way of a neoplasm, but it did show a condition that the pathologist said was nephritis. The patient had had a low blood-pressure. The nephritis followed a pneumonia. I do not see why we should not have a focal nephritis in cases in which the infection has cleared up and yet the pathologic cliange remuins. That is my explanation of some of these cases.

Dr. W. li. Braascif, Rochester, Minn.: As Dr. Chute has suggested, we undoubtedly do occusionally observe cases of chronic renal hematuria with elinical evidences of nephritis, in which the bleeding simulates that of so-called essential hematuria. There is such a large number of eases, however, in which there is no other symptom thun hemnturia, in which, ufter years of observation, no clinienl evidence of nephritis develops and in which little or no evidence of nephritis ean be found on surgical explorntion, that we must conclude that there is some factor other than slight histologic meploritis which causes the hematurin.

We had two enses that were biluteril, in both of which the hematuria was on one side at one time and on the other at another time. I should not regard a bilateral condition a contra-indication to operation, provided that the patient wias not weakened from loss of blool and was otherwise normal. l never have seen simultaneous hematuria in both kidneys.

\section{TIIE VALUE AND LIMI'ATIONS OF FUNCTIONAL RENAL TESTS *}

\section{J. T. GERAGH'IY, M.D. \\ L. G. ROWN'TREE, M.D. BALITMIORE}

In ascertaining the functional crpacity of the kidney, judicious selection of tests is the key to the maximum amount of information from the ininimum expenditure of time and energy. The number of tests is now so large that it is impossible to utilize all in any individual case. It is unnecessary, moreover, since all of the available information is forthcoming at times f'rom a single test or from a proper combination of a small number of tests. In order that the proper selection may be made, however, an insight into the value, limitations, advantages or disndvantages, peculiarities and significance of the findings, together with intimacy with technic concerned, is essential.

Renal functional capncity is usually ascertained in one of two ways: first, by tests of excretory capucity through the quantitative determination of various substances in the urine -dyes, methylene blue, indigocarmin, rosanilin, phenolsulphonephthalein, other chemicals-potassium iodid, luctose, sodium chlorid, urea, sugar following phloridzin and the enzyme dins. tase; secondly, by tests of retention through the quantilative determination of the conecntrution of certain substances in the blood, ions throngh electrical conductivity, molecules through eryoscopy, urea, incongulable nitrogen and cholesterin.

Other tests have been proposed and advocated, but they can be absolutely discarded without loss in l'unctional studies. On account of the approximate paralletism in the excretion of the members of the dye croup, only one need be employed, and on account of its proved superiority, the phenolsulphonephthalein should bo selected. Of the other excretory tests, certuin ones prove of value in relation to certain types of renul disease, ats will be later indicated.

Concerning the tests of retention:

The recent work of Folin and Demnis indientes that the roncentration of urea $0.5 \mathrm{gm}$. and of total incongulable nitrogen $0.0 \mathrm{gm}$. per liter, heretofore considered normal, must no longrer be so considered, since in sixteen strictly normal persous the highest non-protein nitrogen which they found was 26 mug. and urea nitrogen $13 \mathrm{mg}$. per $100 \mathrm{gm}$. blood. Slight nitrogen retention may appurently occur in many diseases, but in our experience in a large number of cases during the older methods

- Read in the Section on Genito-Urinury Iiseases of the Amery can Medicul Assoclation, at the Sixty-Fourth Aunual Sesslon, held ut Minnenpolis, June, 1913 .

Hirom the Genlto-Urinury clinle of the Joluns IIonkins Hospltin und the pharmacoloricul Laboratory of the Johns Hoblins Unt vel'sity.

1. Jiolin and Dennis: Jour. Blol. Chen., 1910, Iv, 20. 